\title{
Sistem Ekonomi dan Fiskal pada Masa Pemerintahan Al-Khulafa Al- Rasyidun (632-661 M)
}

\author{
Bunga M. Shalihah ${ }^{1 *}$ \\ ${ }^{1}$ UIN Raden Fatah Palembang, Indonesia
}

\begin{abstract}
Abstrak: Penelitian ini bertujuan menggambarkan sistem ekonomi dan fiskal pada masa al-khulafa al-rasyidun. Metode penelitian ini menggunakan penelitian kepustakaan. Sehingga hanya melihat tinjauan berdasarkan teori-teori yang ada. Penelitian ini menyimpulkan bahwa pada masa Abu Bakar Ash-Shiddiq fokus pada pengelolaan zakat dan menerapkan konsep balance budget policy pada Baitul Mal. Sedangkan pada Umar bin Khattab fokus pada pendirian Baitul Mal, kepemilikan tanah, dan zakat.
\end{abstract}

Kata Kunci: sistem ekonomi, fiskal, al-khulafa al-rasyidun, ekonomi syariah

\begin{abstract}
This study aims to describe the economic and fiscal system at the time of al-Khulafa alRasyidun. This research method uses library research. So we only see a review based on existing theories. This study concludes that during the time of Abu Bakar Ash-Siddiq focused on zakat management and applied the concept of balance budget policy at Baitul Mal. Meanwhile, Umar bin Khattab focused on the establishment of Baitul Mal, land ownership, and zakat.
\end{abstract}

Keywords: economic system, fiscal, al-khulafa al-rasyidun, sharia economy

\section{Pendahuluan}

Nabi Muhammad Saw. wafat pada 12 Rabiul Awal 10 H/632 M di Madinah. Bersamaan dengan wafatnya Rasulullah Saw., maka berakhir pula masa pemerintahan Beliau. Adapun pasca wafatnya Nabi Muhammad Saw., kepemimpinan Islam dilanjutkan oleh pimpinan Islam dari kalangan sahabat Rasulullah Saw. yang disebut Al-Khulafa al-Rasyidun. Namun ternyata peralihan kepemimpinan pasca wafatnya Rasulullah Saw. tidak berjalan mulus tanpa konflik (Anis, 2016).

Nabi Muhammad Saw. memang telah membentuk sebuah konfederasi, namun tidak meninggalkan wasiat dan pesan penunjukan tentang siapa sahabat atau orang yang akan menjadi khalifah selanjutnya. Di sisi lain, Nabi Muhammad Saw. juga tidak memiliki seorang putra untuk meneruskan kepemimpinannya. Persoalan peralihan kepemimpinan tersebut sedikit banyak telah memecah belah kaum muslimin. Kaum Ansar dan Muhajirin sama-sama beranggapan bahwa orang dari masing-masing kaum merekalah yang pantas menjadi pemimpin.

Kaum Ansar mengutus Sa'ad bin 'Ubadah sebagai khalifah karena orang Ansar merasa telah banyak membantu Nabi dan kaum Muhajirin saat hijrah ke Madinah sehingga Islam begitu cepat diterima dan tersebar. Sedangkan kaum Muhajirin beranggapan bahwa merekalah yang paling berhak

\footnotetext{
* Corresponding Author: Bunga M. Shalihah (bungamaratushshalihah_uin@radenfatah.ac.id). UIN Raden Fatah Palembang, Indonesia
} 
memangku jabatan kepemimpinan sebab pengorbanan yang telah begitu besar hingga meninggalkan seluruh harta dan keluarga di Makkah demi hijrah dan memperjuangkan agama Islam.

Di Balai Tsaqifah, tiga orang tokoh penting yaitu Abu Bakar, Umar bin Khattab, dan Abu Ubaidah, menentukan masa depan Islam. Abu Bakar mengutarakan bahwa terdapat dua hal pokok dalam pemilihan khalifah selanjutnya, yaitu (1) senioritas dan keunggulan suku Quraisy atas sukusuku lainnya pada zaman pra-Nabi; dan (2) syarat utama menjadi anggota al-Mala' (DPR), Nâdi alQaum (MPR), dan kepala suku atau kepala negara adalah minimal usia 40 tahun. Dengan demikian, gugurlah tuntutan kaum Ansar tentang khalifah dari kaum mereka. Kemudian, kabar dan kemungkinan akan klaim tentang jabatan kekhalifan oleh Ali sebagai khalifah otomatis gugur karena belum memenuhi syarat mutlak yang telah ditetapkan untuk menjadi seorang khalifah. Akhirnya dalam pertemuan dan perdebatan sengit di Balai Tsaqifah, seperti yang diusulkan oleh Umar, Abu Bakar terpilih sebagai khalifah dengan senioritas dan asal Abu Bakar dari kaum Quraisy yang menjadi alasan utama (Ramidi, 2020).

Khalifah merupakan pimpinan yang dipilih langsung oleh para sahabat melalui mekanisme yang demokratis. Bagi siapapun yang dipilih, maka sahabat lain berhak untuk memberikan baiat (sumpah setia) pada calon yang terpilih tersebut. Adapun dalam perjalanan Islam periode al-Khulafa al-Rasyidun, terhitung empat khalifah yang memimpin dalam periode tersebut, yaitu Abu Bakar ash-Shiddiq, Umar bin Khattab, Usman bin Affan, dan Ali bin Abi Thalib.

Adapun dalam sejarah kepemimpinannya, masing-masing khalifah memiliki karakter atau ciri khas yang berbeda sehingga membawa corak yang berbeda pula dalam rekam jejak perkembangan Islam dari masa ke masa.

\section{Masa Kekhalifahan Abu Bakar ash-Shiddiq (11-13 H/632-635 M)}

Abu Bakar saat setelah terpilih menjadi khalifah, Beliau langsung memberikan sambutan sebagai berikut:

"Hai Rakyatku, awasilah agar aku menjalankan pemerintahan dengan hati-hati. Aku bukan yang terbaik dia antara kalian; aku membutuhkan semua nasihat dan bantuan kalian. Jika aku benar, dukunglah aku, jika aku salah tegurlah aku. Mengatakan yang benar kepada orang yang ditunjuk untuk memerintah merupakan kesetiaan yang tulus; menyembunyikan adalah pengkhianatan. Menurut pandanganku, yang kuat dan yang lemah adalah sama, kepada keduanya aku ingin berbuat adil. Bila aku taat kepada Allah dan Rasul-Nya, taatlah kepadaku, jika aku mengabaikan hukum Allah dan Rasul-Nya aku tidak berhak untuk kalian taati." (Chamid, 2010).

Begitu cuplikan sambutan Abu Bakar ketika terpilih dan dipercaya untuk menjadi khalifah Islam kala itu. Abu Bakar ash-Shiddiq adalah khalifah Islam pertama yang terpilih dan dipercaya untuk sebagai pemimpin agama dan negara segala setelah wafatnya Rasulullah Saw. Dalam masa pemerintahannya yang tergolong cukup singkat, yakni selama 27 bulan, Abu bakar dihadapkan pada berbagai macam persoalan terutama dari dalam negeri terkait dengan kelompok murtad, nabi palsu, dan para pembangkang zakat yang merebak semenjak wafatnya Rasulullah Saw.

Abu Bakar menghadapi mereka dengan tegas melalui dua alternatif yaitu, tunduk tanpa syarat, atau diperangi dengan mengirim tentara (M. A. 
Karim, 2014). Dalam kondisi tersebut, maka langkah pertama yang dilakukan oleh Abu Bakar adalah menumpas pembangkang dalam Perang Riddah, yaitu perang melawan kemurtadan baru kemudian melakukan perluasan wilayah ke utara untuk menghadapi Romawi dan Persia yang selalu mengancam kedudukan umat Islam (Chamid, 2010; A. Karim, 2004).

Terkait dengan berbagai persoalan yang dihadapi oleh negara, berikut ini adalah langkahlangkah yang dilakukan Abu bakar dalam menyempurnakan ekonomi Islam (Chamid, 2010).

1) Melakukan tindakan hukum yang tegas terhadap para pembangkang zakat. Dalam masa awal pemerintahannya, Abu Bakar dihadapkan pada problematika sosial yang cukup berat. Menurut Imam Suyuti, ketika Rasulullah dikabarkan wafat, banyak sukusuku Arab yang menolak membayar zakat. Untuk mengatasinya, Abu Bakar menggunakan kebijakan disertai dengan pasukan lini depan untuk melakukan pemungutan zakat.

2) Abu Bakar terkenal dengan keakuratan dan ketelitiannya dalam menghitung zakat termasuk dalam kehati-hatiannya memilih seorang amil zakat. Selain perhitungan zakat yang sangat akurat, zakat selalu didistribusikan dalam jangka waktu yang tidak lama sampai habis tidak bersisa dengan prinsip kesamarataan hingga saat beliau wafat, hanya ditemukan satu dirham dalam perbendaharaan negara karena harta yang telah terkumpul di Baitul Mal langsung didistribusikan sehingga tidak ada penumpukan harta. Selain itu, Beliau mengambil alih tanah orang-orang murtad untuk kepentingan umat Islam, membagikan tanah taklukan dan sebagian lain tetap menjadi milik negara.
3) Mengembangkan Baitul Mal dan mengangkat Abu Ubaid sebagai penanggung jawab Baitul Mal.

4) Abu Bakar menerapkan konsep balance budget policy pada Baitul Mal.

5) Secara individu Abu Bakar adalah seorang praktisi akad-akad perdagangan.

Adapun corak kepemimpinan Abu Bakar yang sentralistis membawa hasil yang sangat memuaskan dalam mengatasi berbagai permasalahan yang dihadapi negara pada saat itu hingga terhindar dari perpecahan dan kehancuran.

Menjelang wafat, Abu Bakar menunjuk Umar bin Khattab sebagai penggantinya. Kemudian mengeluarkan kebijakan internal dengan pengembalian kekayaan pada negara karena melihat kondisi negara yang masih dilanda krisis ekonomi. Abu Bakar meminta kalkulasi gaji yang selama ini diterimanya dari Baitul Mal kemudian mengembalikannya dengan menjual sebagian besar tanah yang dimilikinya kemudian memberikan seluruh hasil penjualannya kepada negara. Tidak hanya itu, seluruh fasilitas yang diberikan negara padanya saat ini diinstruksikan untuk dialihkan pada pemimpin berikutnya hingga Umar berkata bahwa Abu Bakar membuat tugas penggantinya menjadi sangat sulit.

Setelah upaya dan pengorbanan penuh dalam masa kepemimpinannya hingga tutup usia, Abu bakar mendapat gelar istimewa oleh para sejarawan sebagai penyelamat Islam setelah Nabi Muhammad Saw. wafat (Abu Bakar is the savior of Islam after prophet Muhammad) (M. A. Karim, 2014).

\section{Masa Kekhalifahan Umar bin Khattab r.a (13- 23 H/634-644 M)}

Setelah Abu Bakar, Umar bin Khattab adalah khalifah kedua setelah wafatnya Rasulullah yang 
dipercaya untuk memegang tanggung jawab sebagai khalifah Islam. Umar mengemban amanah sebagai seorang khalifah selama sepuluh tahun sebelum pada akhirnya beliau wafat karena dibunuh oleh Abu Lu'lu' (orang persia) sebab pemecatan pada Mughirah bin Syuba yang melakukan tindakan pengkhianatan pada negara. Namun demikian, banyak kemajuan yang telah dialami oleh umat Islam dalam masa kepemimpinan Umar. Periode pemerintahan Umar terkenal dengan periode pembangunan dan perubahan Islam, atau bisa disebut sebagai abad keemasan dalam sejarah Islam.

Setelah mengemban tanggung jawab sebagai khalifah, Umar melanjutkan kebijakan perang yang telah dimulai oleh Abu Bakar untuk menghadapi tentara Sasania dan Bizantium. Daerah kekuasaan Islam semakin luas pada masa pemerintahan umar dengan banyaknya tanah taklukan seperti Syiria, Palestina, Mesir, Irak, dan Persia, hingga Umar dijuluki Saint Paul of Islam di dunia barat. Kota Damaskus, yang merupakan kota penting karena merupakan jalur perdagangan internasional, juga berada di bawah kekuasaan Islam saat itu. Dengan demikian dapat dikatakan bahwa pada masa khalifah Umar, pemerintahan Islam telah semakin kokoh (Chamid, 2010; A. Karim, 2004).

Di masa pemerintahannya, wilayah yang berada di bawah kekuasaan negara Islam mulai bertambah dan terdiri dari berbagai suku bangsa, dengan demikian Khalifah Umar berpikir untuk membuat Undang-Undang yang mengatur hubungan antara pemerintahan dengan bangsabangsa tersebut sesuai dengan syariat Islam (AshShalabi, 2008).

Tidak hanya dari aspek pemerintahan, khalifah Umar juga sangat serius dalam menangani perekonomian negara. Dalam aspek ekonomi, sistem ekonomi yang dikembangkan oleh Umar berdasarkan pada keadilan dan kebersamaan dimana disinilah letak ketinggian ajaran Islam. Dalam sistem tersebut, terdapat prinsip pengambilan sebagian kekayaan orang-orang kaya untuk dibagikan kepada orang-orang miskin. Faktor-faktor produksi seperti tanah, modal, tenaga kerja, dan organisasi, tidak lagi berada dalam kekuasaaan individu melainkan pada komunitas. Berikut adalah kebijakan ekonomi pada periode khalifah Umar (Chamid, 2010).

\section{Kebijakan Ekonomi}

Pada masa pemerintahannya, khalifah Umar bin Khattab melakukan penekanan pada cara penanganan urusan kekayaan negara disamping urusan pemerintahan. Adapun dalam menjalankan kebijakan perekonomiannya kala itu, Umar terkenal dengan tiga dasar-dasar kepemimpinannya, yaitu:

1) Negara Islam mengambil kekayaan umum dengan benar, dan tidak mengambil hasil dari kharaj atau harta $f a{ }^{\prime} i$ yang diberikan oleh Allah kecuali dengan mekanisme yang benar.

2) Negara memberikan hak atas kekayaan umum, dan tidak ada pengeluaran kecuali sesuai dengan haknya; dan negara menambah subsidi serta menutup hutang. Adapun kebijakan umar mengenai subsidi negara yaitu keharusan negara untuk memperhatikan apa yang dibelanjakan dengan beberapa kaidah berikut ini:

a) Tujuan pembelanjaan umum harus direncanakan dengan baik sejak awal.

b) Negara harus melaksanakan dengan baik apa yang telah ditetapkan oleh Allah Swt, yakni memberikan zakat kepada mereka yang berhak sesuai dengan tuntunan alQur'an. 
c) Pembagian harta hasil rampasan perang yang berjumlah $1 / 5$ diberikan sesuai dengan apa yang ditetapkan oleh Allah dalam al-Qur'an.

d) Penggunaan harta umum harus sesuai dengan kadar yang dibutuhkan, tanpa pemborosan dan tidak pula terlalu mengirit.

e) Manfaat penggunaan kekayaan negara harus dikembalikan kepada rakyat, bukan pada penguasa atau pejabat. Tidak pula dikhususkan untuk golongan atau kepentingan pribadi dengan mengesampingkan golongan lainnya.

3) Negara tidak menerima harta kekayaan dari hasil yang kotor. Seorang penguasa tidak mengambil harta umum kecuali seperti pungutan harta anak yatim.

Adapun dalam sejarah pemerintahannya, kebijakan yang paling fenomenal adalah kebijakan ekonomi Umar di Sawad (daerah subur). Umar mengeluarkan dekrit yang melarang orang Arab termasuk tentara untuk bertransaksi jual beli tanah di luar Arab. Meskipun menuai berbagai reaksi, Umar memberikan alasan atas kebijakannya tersebut, yaitu mutu tentara Arab yang menurun, produksi menurun, kerugian negara yang mencapai angka $80 \%$ dari pendapatan, dan rakyat akan kehilangan mata pencaharian dan kemudian akan rentan melakukan pemberontakan terhadap negara (M. A. Karim, 2014).

\section{Kebijakan Fiskal}

Unsur-unsur kebijakan fiskal pada masa pemerintahan Umar bin Khattab akan dijelaskan secara lebih rinci pada pembahasan di bawah ini:

1) Pendirian Lembaga Baitul Mal
Dengan bertambahnya luas wilayah kekuasaan di masa pemerintahan Umar, kenaikan pendapatan negarapun meningkat secara signifikan. Oleh karena itu, Khalifah Umar berunding dengan para pemuka sahabat bagaimana dana dari pendapatan Negara akan dikelola agar tidak habis sekaligus untuk kebutuhan Negara dan rakyat. Baitul Mal yang telah dicetuskan oleh Rasulullah Saw. dan diteruskan oleh Abu Bakar menjadi acuan Umar untuk mengembangkan lembaga ini menjadi suatu wadah permanen dan regular.

Pada tahun $16 \mathrm{H}$, bangunan lembaga Baitul Mal pertama kali didirikan di Madinah sebagai pusat dan diikuti pendirian cabang-cabang di daerah ibukota provinsi. Agar lebih teratur Umar lalu menunjuk Abdullah bin Irqam sebagai bendahara negara dengan Abdurrahman bin Ubaid al-Qari sebagai wakilnya (Amalia, 2010).

Selain itu, Umar juga membuat ketentuan bahwa jumlah harta-harta yang ada pada negara haruslah diatur dan diurus oleh pejabat yang berwenang, bukan merupakan urusan khalifah dan pegawainya. oleh karena itu dibuatlah peraturan yang berkaitan dengan kekayaan negara dan disinilah berawal dari adanya pembukuan administrasi (Ash-Shalabi, 2008).

Harta Baitul Mal yang telah dikoordinir oleh pejabat lembaga ditujukan untuk tujuan pendistribusian tidak hanya untuk senjata dan militer, pejabat-pejabat tetapi juga dibagi untuk tunjangan sosial. Umar membagi sistem distribusi ini menjadi beberapa departemen (Amalia, 2010) yaitu: 
a) Departemen Pelayanan Militer

Di dalam departemen ini diharapkan berfungsi untuk mendistribusikan dana bantuan kepada pihak-pihak yang terlibat dalam perang. Jumlah dana bantuan ditentukan oleh jumlah tanggungan keluarga setiap penerima dana.

b) Departemen Kehakiman dan Eksekutif

Departemen ini bertanggungjawab terhadap pembayaran gaji para hakim dan pejabat eksekutif yang telah ditentukan besarannya.

c) Departemen Pendidikan dan Pengembangan Islam

Bantuan dana didistribusikan oleh departemen ini bagi penyebar dan pengembang ajaran Islam beserta keluarganya.

d) Departemen Jaminan Sosial

Fungsi dari departemen jaminan sosial ini adalah untuk mendistribusikan dana bantuan kepada seluruh fakir miskin dan orang-orang yang menderita.

2) Kepemilikan Tanah

Khalifah Umar telah menjadi penguasa dari daerah-daerah sekitar sehingga sangat wajar apabila memperoleh tanah-tanah taklukan yang banyak. Namun dengan jumlah tanah taklukan yang senantiasa bertambah setelah mendapatkan kemenangan dalam perang, justru tanah-tanah tersebut tidak dibagikan kepada kaum muslimin. Hal ini dikarenakan menurut Umar tanah taklukan haruslah dikelola oleh pemilik tanah yang asli, karena dikhawatirkan nantinya akan ada praktik tuan tanah apabila dibagikan secara cuma-cuma bagi kaum muslimin. Selain itu, alasan
Khalifah Umar juga bahwa orang Arab tidak dianjurkan menjadi petani karena bukan ahli dalam pertanian.

3) Zakat

Zakat merupakan penopang kehidupan yang utama dalam pemerintahan Islam dan juga merupakan undang-undang yang pertama dari Allah SWT. Zakat diwajibkan terhadap harta orang-orang Islam yang kaya dan kemudian diberikan kepada orang-orang yang miskin. Antara satu jenis harta dengan yang lain nishabnya (batas maksimal) berbeda-beda (Ash-Shalabi, 2008).

Harta-harta yang harus dizakati adalah hasil pertanian, buah-buahan, emas, perak, harta perniagaan dan binatang ternak. Diwajibkannya zakat bertujuan agar di dalam masyarakat terdapat rasa solidaritas sosial, saling mencintai dan mengasihani antara orang kaya dan miskin. Zakat merupakan ibadah wajib yang dibebankan kepada harta sebagai penyangga kehidupan (Ash-Shalabi, 2008).

Pada masa hidup Nabi Muhammad Saw., jumlah kuda di Arab sangat sedikit terutama kuda yang dimiliki orang-orang Islam untuk digunakan untuk kebutuhan pribadi dan jihad. Sebagai contoh pada saat perang Badar, pasukan Muslim yang berjumlah 313 orang hanya memiliki dua kuda. Pada saat pengepungan Bani Quraisy $(5 \mathrm{H})$ pasukan Muslim memiliki 36 kuda. Pada tahun yang sama, di Hudaibiyah mereka mempunyai sekitar dua ratus kuda. Karena zakat dibebankan atas barang-barang yang memiliki produktifitas, "seorang budak atau seekor kuda yang dimiliki Muslim telah dibebaskan dari zakat" (Chamid, 2010).

Periode selanjutnya, kegiatan beternak dan memperdagangkan kuda dilakukan secara 
besar-besaran di Syiria dan bagian lain dari daerah kekuasaan. Beberapa kuda mempunyai nilai jual yang tinggi (pernah disebutkan bahwa seekor kuda Arab Taghlabi, nilainya diperkirakan sebesar 2000 dirham) dan orangorang Islam terlibat dalam perdagangan ini. Karena perdagangan kuda sedang marak, mereka menanyakan kepada Abu Ubayd, Gubernur Syiria, tentang kewajiban membayar zakat kuda dan budak. Gubernur memberitahu bahwa tidak ada zakat atas keduanya. Kemudian mereka mengusulkan kepada khalifah agar ditetapkan kewajiban zakatnya, tetapi permintaan mereka tidak dikabulkan. Mereka kemudian datang kembali kepada Abu Ubayd dan bersikeras ingin membayar. Akhirnya Gubernur menulis surat kepada Umar (mungkin dilengkapi dengan data yang detail) dan Umar mengistruksikan Gubernur untuk menarik zakat dari mereka dan mendistribusikannya kepada fakir miskin serta budak-budak. Sejak saat itu zakat atas kuda ditetapkan sebesar satu dinar (A. Karim, 2004).

Selain zakat atas kuda, Umar mengenakan khums zakat atas karet yang ditemukan di semenanjung Yaman, antara Aden dan Mukha, dan hasil laut karena barang-barang tersebut dianggap sebagai hadiah dari Allah. Thaif dikenal sebagai tempat peternakan lebah, dan menurut beberapa riwayat Bilal datang kepada nabi dengan ushr atas madunya dan memintanya agar lembah Salba dicadangkan untuknya. Permintaannya ini diterima oleh nabi (Chamid, 2010).

Pada masa Umar, Gubernur Thaif melaporkan bahwa pemilik sarang lebah tidak membayar ushr tetapi menginginkan sarang-sarang lebah tersebut yang dilindungi secara resmi. Umar mengatakan bahwa bila mereka mau membayar ushr maka sarang lebah mereka akan dilindungi. Namun jika menolak, mereka tidak akan memperoleh perlindungan. Menurut riwayat Abu Ubaid, Umar membedakan madu yang diperoleh dari lading. Zakat yang ditetapkan adalah seperduapuluh untuk madu yang pertama dan sepersepuluh untuk madu jenis kedua (A. Karim, 2004).

4) Ushr

Sebelum Islam datang, setiap suku atau kelompok suku yang tinggal di pedesaan biasa membayar pajak (ushr) pembelian dan penjualan (Maqs). Besarnya 10 persen dari nilai barang atau satu dirham setiap transaksi. Tetapi setelah negara Islam berdiri di negara Arab. Nabi mengambil inisiatif untuk mendorong usaha perdagangan dengan menghapus bea masuk antar provinsi yang masuk dalam daerah kekuasaan dan masuk dalam perjanjian yang ditandatangani oleh beliau bersama suku-suku yang tunduk kepada kekuasaannya. Secara jelas dikatakan bahwa pembebanan sepersepuluh hasil pertanian kepada pedagang Manbij (Hierapolis) dikatakan sebagai yang pertama dalam masa Umar (Chamid, 2010).

Orang-orang Manbij adalah orang-orang harbi yang meminta izin kepada khalifah memasuki negara Muslim untuk melakukan perdagangan dengan membayar sepersepuluh dari nilai barang. Setelah berkonsultasi dengan beberapa sahabat yang lain, Umar memberikan izin. Tetapi terdapat kasus khusus ketika Abu Musa Al-Asy'ari menulis surat kepada Umar yang menyatakan bahwa pedagang Muslim dikenakan pajak sepersepuluh di tanah harbi. Khalifah Umar menyarankan agar membalasnya dengan mengenakan pajak pembelian dan penjualan yang normal kepada 
mereka. Ada perbedaan versi menurut tingkat ukurannya. Tingkat ukuran yang paling umum digunakan adalah 2,5\% untuk pedagang Muslim, 5\% untuk kafir dzimmi, dan 10\% untuk kafir harbi dengan asumsi harga barang melebihi dua ratus dirham (A. Karim, 2004).

Ushr dibebankan kepada suatu barang hanya sekali dalam setahun. Umar menginstruksikan para pegawainya agar tidak menarik $u s h r$ dua kali dalam setahun walaupun barang tersebut diperbarui. Pos pengumpulan ushr terletak di berbagai tempat yang berbeda-beda, termasuk di ibukota (Chamid, 2010).

5) Sedekah dari Non-Muslim

"Tidak ada Ahli Kitab yang membayar sedekah atas ternaknya kecuali orang Kristen Bani Taghlibi yang keseluruhan kekayaannya terdiri dari ternak. Mereka membayar dua kali lipat dari yang dibayar Muslim". Bani Taghlib adalah suku Arab Kristen yang menderita akibat peperangan. Umar mengenakan jizyah kepada mereka, tetapi mereka terlalu gengsi sehingga menolak membayar jizyah dan malah membayar sedekah. Namun Ibn Zuhra memberikan alasan untuk kasus mereka. Ia mengatakan pada dasarnya tidaklah bijaksana memperlakukan mereka seperti musuh dan seharusnya keberanian mereka menjadi aset negara. Umar pun memanggil mereka dan menggandakan sedekah yang harus mereka bayar, dengan syarat mereka setuju untuk tidak membabtis seorang anak atau memaksanya untuk menerima kepercayaan mereka. Mereka pun menyetujui dan menerima membayar sedekah ganda (Chamid, 2010).

6) Mata Uang

Pada masa nabi dan sepanjang masa pemerintahan al-Khulafaar-Rasyidun, koin mata uang asing dengan berbagai bobot telah dikenal di Jazirah Arab, seperti dinar, sebuah koin emas, dan dirham, sebuah koin perak. Bobot dinar adalah sama dengan satu mitsqal atau sama dengan dua puluh qirat atau seratus grains of barley. Oleh karena itu, rasio antara satu dirham dan satu mitsqal adalah tujuh per sepuluh (A. Karim, 2004).

7) Klasifikasi dan Alokasi Pendapatan Negara

Pada saat pemerintahan khalifah Umar bin Khattab, pendapatan meningkat tajam dan Baitul Mal didirikan secara permanen di pusat ibukota dan ibukota provinsi. Khalifah Umar bin Khattab mengklasifikasi pendapatan negara menjadi empat bagian, yaitu:

Tabel 1. Klasifikasi Pendapatan Negara

\begin{tabular}{|c|c|c|}
\hline No & Jenis Pendapatan & Tujuan Penggunaan \\
\hline 1 & Zakat dan Ushr & $\begin{array}{l}\text { Pendapatan } \\
\text { didistribusikan dalam } \\
\text { tingkat lokal. Jika ada } \\
\text { kelebihan (surplus), maka } \\
\text { kelebihan itu di kirim ke } \\
\text { Baitul Mal pusat } \\
\text { (Madinah) dan dibagikan } \\
\text { kepada delapan asnaf. }\end{array}$ \\
\hline 2 & Khums dan sedakah & $\begin{array}{lr}\text { Pendapatan } & \text { ini } \\
\text { didistribusikan kepada } \\
\text { fakir-miskin atau untuk } \\
\text { membiayai mereka yang } \\
\text { sedang mencari } \\
\text { kesejahteraan, tanpa } \\
\text { diskriminasi apakah ia } \\
\text { seorang Muslim atau } \\
\text { bukan. }\end{array}$ \\
\hline 3 & $\begin{array}{l}\text { Kharaj, Fai', jizyah, } \\
\text { Ushr } \\
\text { perdagangan), dan } \\
\text { sewa tanah }\end{array}$ & $\begin{array}{l}\text { Pendapatan ini digunakan } \\
\text { untuk membayar dana } \\
\text { pension dan dana bantuan } \\
\text { serta untuk menutupi biaya } \\
\text { operasional administrasi, } \\
\text { kebutuhan militer dan } \\
\text { sebagainya. }\end{array}$ \\
\hline 4 & Pendapatan lain-lain & $\begin{array}{l}\text { Pendapatan ini digunakan } \\
\text { untuk membayar para } \\
\text { pekerja, pemeliharaan } \\
\text { anak-anak terlantar, dan } \\
\text { dana sosial lainnya. }\end{array}$ \\
\hline
\end{tabular}


Pendapatan yang diterima di Baitul Mal terbagi dalam empat bagian berikut:

a) Pendapatan yang diperoleh dari zakat dan ushr yang dikenakan terhadap Muslim

b) Pendapatan yang diperoleh dari khums dan shadaqah

c) Pendapatan yang diperoleh dari kharaj, fai, jizyah, ushr, dan sewa tetap tahunan tanah-tanah yang diberikan.

d) Berbagai macam pendapatan yang diterima dari berbagai sumber.

8) Pengeluaran

Di antara alokasi pengeluaran dari harta Baitul Mal tersebut, dana pension merupakan pengeluaran Negara yang paling penting. Prioritas berikutnya adalah dana pertahanan Negara dan dana pembangunan (A. Karim, 2004).

Seperti yang telah dijelaskan, Khalifah Umar menempatkan dana pension di tempat pertama dalam bentuk rangsum bulanan (arzaq) pada tahun $18 \mathrm{H}$, dan selanjutnya pada tahun $20 \mathrm{H}$ dalam bentuk rangsum tahunan (atya). Awalnya dana pensiun ditetapkan untuk mereka yang akan bergantung dan pernah bergabung dalam kemiliteran, karena merekalah yang akan menjadi dan berpotensial menjadi tentara. Dalam terminology modern kita dapat menyebut dana pension ini sebagai gaji regular angkatan bersenjata dan tentara cadangan serta penghargaan bagi orang-orang yang telah berjasa diberi pension kehormatan (sharaf) seperti yang diberikan kepada para istri Rasulullah atau para janda dan anak-anak pejuang yang telah wafat. Non-Muslim yang bersedia ikut dalam kemiliteran juga mendapat penghargaan serupa (Chamid, 2010).

\section{Kesimpulan}

Penelitian ini menyimpulkan bahwa pada masa Abu Bakar Ash-Shiddiq fokus pada pengelolaan zakat dan menerapkan konsep balance budget policy pada Baitul Mal. Sedangkan pada Umar bin Khattab fokus pada pendirian Baitul Mal, kepemilikan tanah, dan zakat.

\section{Daftar Pustaka}

Amalia, P. D. (2010). Peran Lembaga Amil Zakat Dalam Pemberdayaan Ekonomi Masyarakat Miskin. Universitas Airlangga.

Anis, M. (2016). Perkembangan Politik Masa AlKhulafa Al-Rasyidun. Jurnal Al-Qalam: Jurnal Kajian Islam \& Pendidikan, 8(1), 5272.

Ash-Shalabi, A. M. (2008). The Great Leader of Umar bin Al-Khattab: Kisah Kehidupan \& Kepemimpinan Khalifah Kedua. Pustaka Al Kautsar.

Chamid, N. (2010). Jejak Langkah Sejarah Pemikiran Ekonomi Islam. Pustaka Pelajar.

Karim, A. (2004). Sejarah Pemikiran Ekonomi islam. Raja Grafindo Persada.

Karim, M. A. (2014). Sejarah Pemikiran dan peradaban Islam. Pustaka Book Publisher.

Ramidi, A. (2020). New Era and Islam (Ketegangan Islam Terhadap Makna Realitas). Al-I'lam: Jurnal Komunikasi Dan Penyiaran Islam, 3(2), 53-60. 